\title{
Unilateral Versus Bilateral Biliary Drainage for Post-Transplant Anastomotic Stricture
}

\author{
Jin Ho Choi and Woo Hyun Paik \\ Department of Internal Medicine and Liver Research Institute, Seoul National University Hospital, Seoul National University College of \\ Medicine, Seoul, Korea
}

Living donor liver transplantation is the most common type of liver transplantation in Asia. Post-transplant biliary stricture is frequent in living donor liver transplantation, and endoscopic management is considered to be the treatment of choice. However, endoscopic management is still challenging in patients who undergo right lobe living donor liver transplantation because of the anatomical alteration. In this article, we reviewed the recently updated results for proper endoscopic biliary drainage in post-living donor liver transplantation anatomical biliary stricture and compared unilateral and bilateral drainage. Clin Endosc 2020;53:255-260

Key Words: Biliary stent; Biliary stricture; Endoscopic retrograde cholangiopancreatography; Living donor liver transplantations

\section{INTRODUCTION}

Living donor liver transplantation (LDLT) is the most common type of liver transplantation (LT) in Asia. ${ }^{1}$ Duct-to-duct anastomosis is currently the most frequently used technique for the reconstruction of bile ducts during LDLT. This is because it is physiologic and enables the use of an endoscopic approach if biliary complications occur after surgery. ${ }^{2}$ Biliary stricture occurs in approximately $13 \%-14 \%$ of all patients undergoing LT, and more frequently in LDLT than in deceased donor LT (DDLT). ${ }^{3-5}$ Anastomotic biliary strictures (ABSs) account for approximately $80 \%$ of all post-transplant biliary strictures, and are usually single, short (up to $5 \mathrm{~mm}$ ), and localized to the anastomosis site. ${ }^{6}$

Endoscopic management is currently considered the treatment of choice for ABS. However, endoscopic management is

Received: March 28, 2020 Revised: April 23, 2020

Accepted: April 27, 2020

Correspondence: Woo Hyun Paik

Department of Internal Medicine and Liver Research Institute, Seoul National University Hospital, 101 Daehak-ro, Jongno-gu, Seoul 03080, Korea

Tel: +82-2-2072-3536, Fax: +82-2-762-9662, E-mail: whpaik@snuh.org

ORCID: https://orcid.org/0000-0001-8708-3280

(c) This is an Open Access article distributed under the terms of the Creative Commons Attribution Non-Commercial License (http://creativecommons.org/ licenses/by-nc/3.0) which permits unrestricted non-commercial use, distribution, and reproduction in any medium, provided the original work is properly cited. still challenging among patients who undergo right lobe LDLT because of the anatomical alterations. In right lobe LDLT patients, the right anterior and right posterior segmental ducts of the donor are connected to the recipient's bile duct (Fig. 1). Even duodenal intubation with an approach to the ampulla is sometimes difficult due to the absence of the left lobe of the liver in right lobe LDLT patients. The shorter bile ducts and the narrower confluence in the right lobe with two bile duct anastomotic sites that connect the right anterior and right posterior segmental duct also make endoscopic procedures difficult. ${ }^{7,8}$ It is, therefore, important to choose the endoscopic drainage technique with the optimal effect and the lowest risk of procedure-related adverse events. In this article, we reviewed recent studies on endoscopic biliary drainage in post-LDLT ABS. We also compared unilateral and bilateral drainage in post-LDLT ABS.

\section{ANASTOMOTIC BILIARY STRICTURE AFTER LDLT}

ABS is mainly caused by ischemic damage, which is known to cause more damage to biliary epithelial cells than to hepatocytes or surrounding vascular endothelial cells. ${ }^{9}$ Reduced blood supply to the anastomosis and multiple small ducts in 


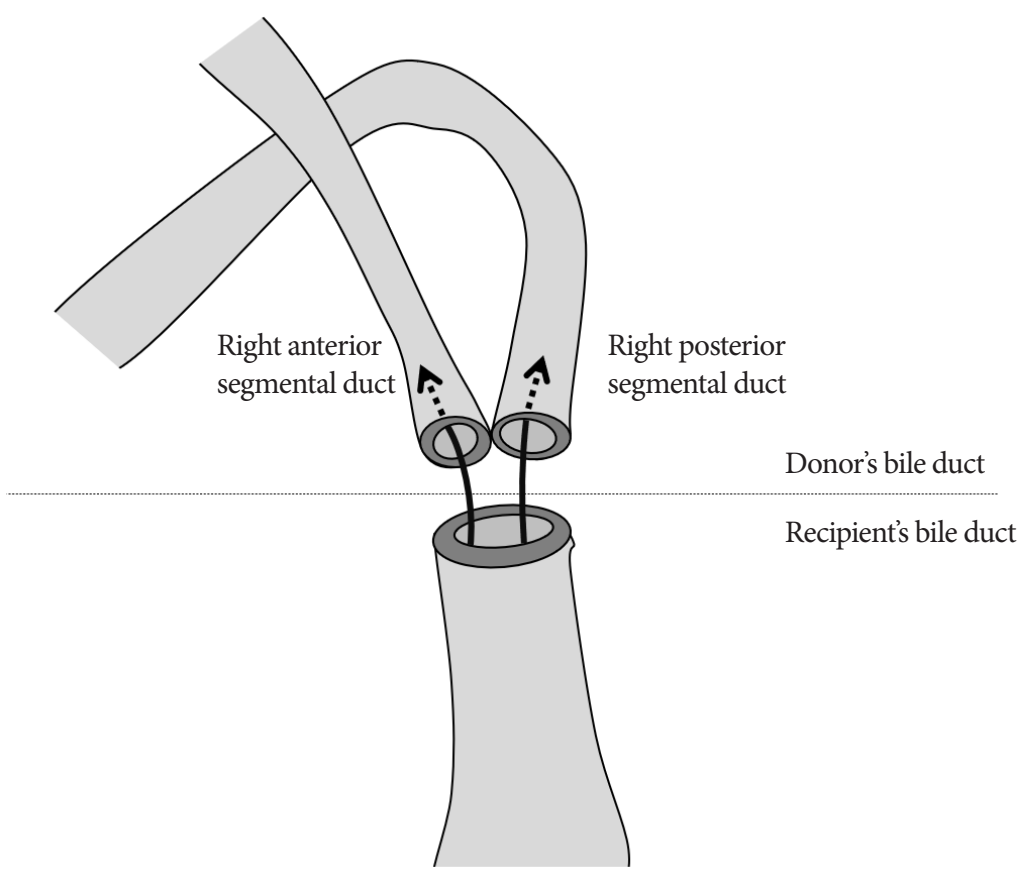

Fig. 1. Schematic diagram of biliary reconstruction during right lobe living donor liver transplantation.

the graft can be caused by differences in diameter between the donor and recipient bile ducts. ${ }^{10}$ In addition, acute cellular rejection, recurrent biliary infection, and postoperative use of a biliary drainage catheter may contribute to the development of ABS. ${ }^{10-12}$ The skill and experience of the surgeon performing the LDLT is also considered a factor in the formation of ABS. ${ }^{13}$ In LDLT patients, strictures are often very tight and twisted due to the presence of dense fibrotic tissue and transplanted liver hypertrophy, making this procedure more challenging. ${ }^{8}$ Several risk factors for postoperative biliary stricture, such as multiple bile duct grafts, bile leakage, and hepatic artery stenosis, have been reported in the literature. ${ }^{14}$

It is necessary to treat ABS after LT repeatedly for a long time, and inappropriate treatment may have a detrimental effect on the graft and patient survival. When ABS is adequately managed, it does not affect the overall survival of LDLT patients. ${ }^{14-17}$

\section{NON-SURGICAL BILIARY DRAINAGE FOR ANASTOMOTIC BILIARY STRICTURE AFTER LDLT}

Biliary stricture that occurs after LDLT should be optimally managed using all available methods. Recently, surgical treatment has been used mainly in refractory cases that cannot be managed using other methods. Non-surgical treatment methods for post-LT biliary stricture include endoscopic and percutaneous approaches. The former is the primary modality of choice in most institutions.

Generally, in endoscopic approaches, biliary stents are placed along the preceding guidewire through the ABS, and the details of each procedure are decided by the operator after considering various clinical and technical aspects. These approaches generally involve the temporary placement of single or multiple plastic stents (PSs) after balloon dilation. ${ }^{18}$ The clinical outcomes of endoscopic approaches in post-LDLT ABS with duct-to-duct anastomosis reported by previous studies are summarized in Table $1 .{ }^{14,16,19-30}$ The reported rate of initial successful management with endoscopic approaches ranges from $46.7 \%$ to $88.6 \%$. The reported resolution rate of non-surgical management ranges between $36.9 \%$ and $100 \%$. A median of 1.4-6.3 endoscopic sessions and percutaneous back-ups are performed during the follow-up period. ${ }^{14,16,19-30}$ ABSs that develop after LDLT can be technically challenging to manage using endoscopic approaches because of the small diameter of donor intrahepatic ducts. The strictures that develop at each of the two biliary anastomosis sites also hamper endoscopic approaches. As a result, even after prolonged intervention, the rate of successful treatment of ABSs after LDLT is relatively low. Single operator peroral cholangioscopy has recently enabled the passage of a guidewire through the 
Table 1. Literature Review of Clinical Outcomes through Endoscopic Approach to Anastomotic Biliary Stricture after Living Donor Liver Transplantation with Duct to Duct Anastomosis

\begin{tabular}{|c|c|c|c|c|c|c|c|c|c|}
\hline Study & $\begin{array}{l}\text { No. of } \\
\text { enrolled pa- } \\
\text { tients (No. of } \\
\text { patients who } \\
\text { had multiple } \\
\text { anastomotic } \\
\text { stricture) }\end{array}$ & $\begin{array}{l}\text { Follow- } \\
\text { up } \\
\text { period } \\
\text { (mo) }\end{array}$ & $\begin{array}{l}\text { Initial suc- } \\
\text { cess rate of } \\
\text { endoscopic } \\
\text { approach (\%) }\end{array}$ & $\begin{array}{l}\text { Sessions } \\
\text { of endos- } \\
\text { copy } \\
\text { during } \\
\text { follow-up } \\
\text { (median) }\end{array}$ & $\begin{array}{l}\text { Stricture } \\
\text { resolution rate } \\
\text { with non-sur- } \\
\text { gical approach } \\
(\%)\end{array}$ & $\begin{array}{l}\text { Needs of } \\
\text { percutaneous } \\
\text { approach (\%) }\end{array}$ & 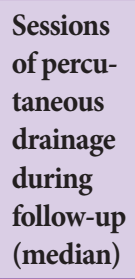 & $\begin{array}{l}\text { Surgery } \\
(\%)\end{array}$ & $\begin{array}{l}\text { Recurrence } \\
\text { rate }(\%)\end{array}$ \\
\hline You et al. $(2019)^{19}$ & $110(110)$ & 56.2 & $60.0(66 / 110)$ & 4 & $61.8(68 / 110)$ & $\mathrm{N} / \mathrm{A}$ & 8.7 & 0 & N/A \\
\hline Jang et al. $(2017)^{20}$ & 35 (N/A) & 18.7 & $82.9(29 / 35)$ & $\mathrm{N} / \mathrm{A}$ & $100(35 / 35)$ & $\mathrm{N} / \mathrm{A}$ & $\mathrm{N} / \mathrm{A}$ & 0 & $20.7(6 / 29)$ \\
\hline Hsieh et al. $(2013)^{22}$ & $38(10)$ & 74.2 & $84.2(32 / 38)$ & 4 & $100(35 / 35)$ & $15.8(6 / 38)$ & N/A & 0 & $21(8 / 38)$ \\
\hline Na et al. $(2014)^{16}$ & 65 (N/A) & 45.7 & $81.5(53 / 65)$ & 3.2 & $89.2(58 / 65)$ & $13.8(9 / 65)$ & N/A & $4.6(3 / 65)$ & N/A \\
\hline Kurita et al. $(2013)^{21}$ & $88(\mathrm{~N} / \mathrm{A})$ & 53 & $88.6(78 / 88)$ & 1.4 & N/A & N/A & N/A & N/A & N/A \\
\hline Lee et al. $(2011)^{23}$ & $137(36)$ & N/A & $46.7(64 / 137)$ & 4.8 & $100(137 / 137)$ & $53.3(73 / 137)$ & N/A & 0 & N/A \\
\hline Kim et al. $(2011)^{24}$ & 147 (N/A) & 43 & $55.8(82 / 147)$ & 6.3 & $36.9(52 / 141)$ & $44.2(65 / 147)$ & N/A & N/A & $11.5(6 / 52)$ \\
\hline Chang et al. $(2010)^{25}$ & $121(9)$ & 33 & $63.7(72 / 113)$ & 3.2 & N/A & $28.3(32 / 113)$ & N/A & $4.1(5 / 121)$ & N/A \\
\hline Kato et al. $(2009)^{27}$ & $41(14)$ & 29.1 & $75.6(31 / 41)$ & 5 & $51.2(21 / 41)$ & $24.4(10 / 41)$ & N/A & $4.9(2 / 41)$ & $25(7 / 28)$ \\
\hline Seo et al. $(2009)^{14}$ & $29(\mathrm{~N} / \mathrm{A})$ & 31 & $62.1(18 / 29)$ & 2.3 & $96.6(28 / 29)$ & $51.7(15 / 29)$ & N/A & $3.4(1 / 29)$ & $30(6 / 20)$ \\
\hline Kim et al. $(2009)^{26}$ & $60(6)$ & 6 & $63.3(38 / 60)$ & 2 & $96.7(58 / 60)$ & $68.2(15 / 22)$ & N/A & N/A & $13.2(5 / 38)$ \\
\hline Yazumi et al. $(2006)^{28}$ & $75(19)$ & N/A & $64.0(48 / 75)$ & N/A & $76(57 / 75)$ & $36(27 / 75)$ & N/A & $16(12 / 75)$ & $10.7(3 / 28)$ \\
\hline Tsujino et al. $(2006)^{29}$ & $17(8)$ & 10 & $70.6(12 / 17)$ & 3 & $82.4(14 / 17)$ & $5.9(1 / 17)$ & N/A & $23.5(4 / 17)$ & $44.4(4 / 9)$ \\
\hline Hisatsune et al. $(2003)^{30}$ & $22(\mathrm{~N} / \mathrm{A})$ & N/A & $63.6(14 / 22)$ & N/A & N/A & $18.2(4 / 22)$ & N/A & $27.3(6 / 22)$ & N/A \\
\hline
\end{tabular}

N/A, not applicable.

stricture under direct visualization in cases where the use of conventional endoscopic approaches is difficult. ${ }^{31,32}$

Percutaneous approaches are often used for rescue therapy in cases where an endoscopic approach was unsuccessful. A percutaneous approach is required in $5.9 \%$ to $73.7 \%$ of cases during endoscopic management. ${ }^{14,16,22-30}$ A percutaneous procedure is used for the estimation of stricture resolution and for stent replacement periodically or simultaneously during an endoscopic session in which the rendezvous method is used. In addition, magnetic compression anastomosis was reported to be successful in patients with refractory ABS after LDLT. ${ }^{33}$

As the management of post-LDLT ABS requires a considerable number of repetitive treatments, the failure of any approach does not mean that it will never be used again. Since the available methods are complementary to each other, it is essential to use the appropriate combination of methods to achieve stricture resolution.

\section{OPTIMAL ENDOSCOPIC DRAINAGE STRATEGIES FOR ANASTOMOTIC BILIARY STRICTURE AFTER LDLT}

\section{Endoscopic stenting strategies: unilateral versus bilateral drainage in patients with right lobe living donor liver transplantation}

Despite its importance, studies that investigate the optimal drainage volume during the treatment of post-LDLT ABS are scarce. For this reason, we estimated the appropriate drainage volume indirectly by examining the results of a malignant hilar obstruction (MHO). ABS after LDLT with duct-to-duct anastomosis seems to be structurally similar to advanced types of $\mathrm{MHO}$ (Bismuth type III or IV). Theoretically, the right lobe of the liver accounts for $55 \%-60 \%$, the left lobe accounts for $30 \%-35 \%$, and the caudate lobe accounts for $10 \%$ of the liver volume. ${ }^{11}$ In the past, approximately $25 \%$ unilateral drainage was considered sufficient for palliative biliary decompression in $\mathrm{MHO}{ }^{33-35}$ However, the importance of draining more than $50 \%$ of the viable liver volume was demonstrated. ${ }^{36-38}$ For bil- 
iary stricture in LDLT patients, unilateral drainage may not be sufficient, given the smaller absolute liver volume and the effects of possible underlying diseases.

Although a tight ABS after LDLT with small anastomotic bile duct diameters and acute angulation of the biliary tract may not physically allow the placement of multiple stents, some studies have suggested that an aggressive endoscopic approach with placement of the highest number of stents possible might produce better clinical outcomes. ${ }^{16,22,39}$ Hsieh et al., reported an initial endoscopic technical success rate of $84 \%$ and successful resolution of ABS in all patients, with a median of three stents per procedure and a median follow-up period of 74.2 months. ${ }^{22}$ In this study, after the initial insertion of the PSs across the stricture, the maximum number of additional stents was placed after proper balloon dilatation. Using a similar method to insert as many stents as possible with the maximal diameter of the stents, $\mathrm{Na}$ et al. reported an $81.5 \%$ initial endoscopic technical success rate and an $89.2 \%$ stricture resolution rate with repeated endoscopic sessions during a median follow-up period of 45.7 months. ${ }^{16}$ Although these non-comparative retrospective studies on maximal stenting strategies reported particularly high success rates in relatively large numbers of patients with long-term follow-up periods, the numbers of endoscopy sessions required until stricture resolution were not significantly different from those reported by studies that involved other strategies. Therefore, a conservative interpretation of the superiority of the maximal stenting strategy is necessary.

In cases where multiple stents can be inserted, it is necessary to consider the drainage volume of the transplanted liver. Bilateral drainage may be more efficient than unilateral drainage as the index procedure as it allows sufficient drainage of the transplanted liver. In a recent large single-center retrospective study that involved 110 right lobe LDLT patients with two duct-to-duct anastomosis sites, most patients required bilateral drainage using endoscopic and/or percutaneous methods more than once during the follow-up period. ${ }^{19}$ Several clinical outcome measures, including clinical success, complication, and mortality rates were not significantly different between the unilateral and bilateral drainage groups. However, 63.6\% (35 of 55) of the patients with unilateral drainage eventually underwent bilateral drainage as well, $64.5 \%$ (71 of 110) of the patients underwent bilateral drainage more than once, and $24.5 \%$ (27 of 110) had ABS resolution with only unilateral biliary drainage during the follow-up period. Even though bilateral stenting was technically challenging, the authors suggested that maximal drainage should be attempted in patients with post-LDLT ABS. They concluded that the endoscopic and percutaneous approaches are complementary.

\section{Other technical aspects of endoscopic management}

The conventional treatment for post-LDLT ABS involves repeated biliary plastic stenting and regular balloon dilatation until the stricture is resolved. PSs have mainly been used in the repetitive endoscopic management of these patients, and repeated hospital admissions for multiple PS insertions by endoscopic retrograde cholangiopancreatography (ERCP) seem to be inevitable. ${ }^{23,40}$ Some endoscopists have recommended the use of the "inside-stent" method, as it has shown positive results in prolonging stent patency and maintaining the advantages of duct-to-duct biliary anastomosis for post-LDLT ABS by preventing sphincterotomy. However, further prospective randomized studies are needed to prove its superiority to conventional methods. ${ }^{21,28-30}$ Several recent studies on covered self-expandable metal stents (SEMS) for benign biliary strictures, including randomized controlled studies on ABS after DDLT, have reported good stricture resolution rates with fewer ERCP sessions. ${ }^{40-43}$ In post-LDLT ABS, although some studies have reported promising results, limited experience and possible stent migration are still regarded as disadvantages of using SEMS in these cases. ${ }^{20,44-46}$

\section{Stent maintenance period and endoscopic treatment intervals}

PSs are usually exchanged every three months to prevent stent dysfunction based on the protocol for benign biliary stricture in non-LT cases. Studies have reported that a mean interval of two to six months is needed between ERCP sessions and that one year might be needed to achieve ABS resolution. ${ }^{18,22,24,28,47,48}$ Although some effort has been made to reduce the stent placement period through the employment of shorter stent change intervals and the use of maximal stent diameters, little evidence has been provided to support the recognition of these methods as standard methods. ${ }^{39,49}$ A sufficient period for stent placement may be necessary, as stricture recurrences seem to be frequent in patients with short stenting durations. ${ }^{14}$ Among LDLT patients undergoing balloon dilation and/or conventional PS placement, the reported rates of stricture recurrence range from $10.7 \%$ to $44.4 \%$ during a median follow-up period of 6 to 74.2 months. ${ }^{14,20,22,24,26-29}$ According to previous studies, the majority of stricture recurrences occurred within one year after stent removal. As most recurrent strictures are successfully managed via repeated endoscopic procedures, only a minority of patients require percutaneous transhepatic biliary drainage or surgery. A schematic diagram that summarizes the most optimal drainage strategy is shown in Fig. 2. 


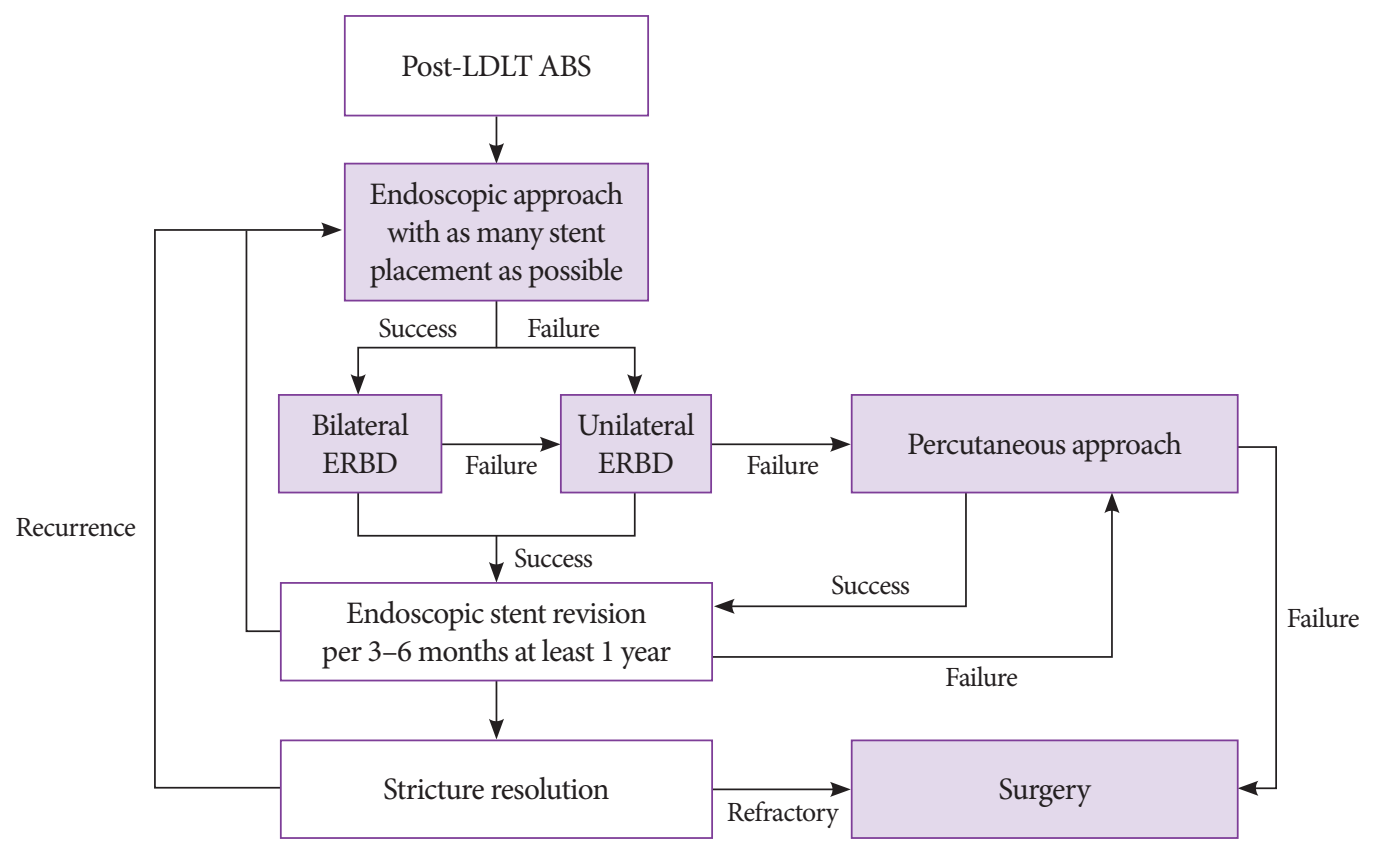

Fig. 2. A schematic diagram of the proper drainage strategy for anastomotic biliary stricture (ABS) after living donor liver transplantation. ERBD, endobiliary retrograde biliary drainage; LDLT, living donor liver transplantation.

\section{CONCLUSIONS}

Post-LT ABS still occurs in many patients, and most frequently in patients undergoing LDLT. The endoscopic approach for post-LDLT ABS is considered the first-line method and generally involves the insertion and regular replacement of multiple PSs after balloon dilation. To determine the optimal protocol for the endoscopic treatment of LDLT patients, various aspects, such as proper drainage volume of the transplanted liver, technical skills in performing the endoscopic procedures, and stent characteristics, should be considered. Studies indicate that the strategy of inserting as many stents as possible during the index endoscopic procedure and, if possible, performing bilateral drainage may be advantageous. The percutaneous approach can be used as a complementary or back-up therapy to increase the success rate of the endoscopic approach, whereas surgery can be reserved for refractory cases.

Conflicts of Interest

The authors have no financial conflicts of interest.

ORCID

Jin Ho Choi: https://orcid.org/0000-0003-2758-1370

\section{REFERENCES}

1. Rela M, Reddy MS. Living donor liver transplant (LDLT) is the way for- ward in Asia. Hepatol Int 2017;11:148-151.

2. Ishiko T, Egawa H, Kasahara M, et al. Duct-to-duct biliary reconstruction in living donor liver transplantation utilizing right lobe graft. Ann Surg 2002;236:235-240.

3. Santosh Kumar KY, Mathew JS, Balakrishnan D, et al. Intraductal transanastomotic stenting in duct-to-duct biliary reconstruction after living-donor liver transplantation: a randomized trial. J Am Coll Surg 2017;225:747-754.

4. Wan P, Yu X, Xia Q. Operative outcomes of adult living donor liver transplantation and deceased donor liver transplantation: a systematic review and meta-analysis. Liver Transpl 2014;20:425-436.

5. Akamatsu N, Sugawara Y, Hashimoto D. Biliary reconstruction, its complications and management of biliary complications after adult liver transplantation: a systematic review of the incidence, risk factors and outcome. Transpl Int 2011;24:379-392.

6. Balderramo D, Navasa M, Cardenas A. Current management of biliary complications after liver transplantation: emphasis on endoscopic therapy. Gastroenterol Hepatol 2011;34:107-115.

7. Mortele KJ, Ros PR. Anatomic variants of the biliary tree: MR cholangiographic findings and clinical applications. AJR Am J Roentgenol 2001;177:389-394.

8. Tsujino T, Isayama H, Kogure H, Sato T, Nakai Y, Koike K. Endoscopic management of biliary strictures after living donor liver transplantation. Clin J Gastroenterol 2017;10:297-311.

9. Noack K, Bronk SF, Kato A, Gores GJ. The greater vulnerability of bile duct cells to reoxygenation injury than to anoxia. Implications for the pathogenesis of biliary strictures after liver transplantation. Transplantation 1993;56:495-500.

10. Rao HB, Prakash A, Sudhindran S, Venu RP. Biliary strictures complicating living donor liver transplantation: problems, novel insights and solutions. World J Gastroenterol 2018;24:2061-2072.

11. Bismuth H. Surgical anatomy and anatomical surgery of the liver. World J Surg 1982;6:3-9.

12. Paik WH, Lee SH, Ryu JK, et al. Long-term clinical outcomes of biliary cast syndrome in liver transplant recipients. Liver Transpl 2013;19:275282.

13. Lin TS, Chen CL, Concejero AM, et al. Early and long-term results of 
routine microsurgical biliary reconstruction in living donor liver transplantation. Liver Transpl 2013;19:207-214.

14. Seo JK, Ryu JK, Lee SH, et al. Endoscopic treatment for biliary stricture after adult living donor liver transplantation. Liver Transpl 2009;15:369380.

15. Chok KS, Chan SC, Cheung TT, et al. Bile duct anastomotic stricture after adult-to-adult right lobe living donor liver transplantation. Liver Transpl 2011;17:47-52.

16. Na GH, Kim DG, Choi HJ, Han JH, Hong TH, You YK. Interventional treatment of a biliary stricture after adult right-lobe living-donor liver transplantation with duct-to-duct anastomosis. HPB (Oxford) 2014;16:312-319.

17. Kyoden Y, Tamura S, Sugawara Y, et al. Incidence and management of biliary complications after adult-to-adult living donor liver transplantation. Clin Transplant 2010;24:535-542.

18. Zoepf T, Maldonado-Lopez EJ, Hilgard P, et al. Balloon dilatation vs. balloon dilatation plus bile duct endoprostheses for treatment of anastomotic biliary strictures after liver transplantation. Liver Transpl 2006;12:88-94.

19. You MS, Paik WH, Choi YH, et al. Optimal biliary drainage for patients with biliary anastomotic strictures after right lobe living donor liver transplantation. Liver Transpl 2019;25:1209-1219.

20. Jang SI, Sung SY, Park H, Lee KH, Joo SM, Lee DK. Salvage therapy using self-expandable metal stents for recalcitrant anastomotic strictures after living-donor liver transplantation. Therap Adv Gastroenterol 2017;10:297-309.

21. Kurita A, Kodama Y, Minami R, et al. Endoscopic stent placement above the intact sphincter of Oddi for biliary strictures after living donor liver transplantation. J Gastroenterol 2013;48:1097-1104.

22. Hsieh TH, Mekeel KL, Crowell MD, et al. Endoscopic treatment of anastomotic biliary strictures after living donor liver transplantation: outcomes after maximal stent therapy. Gastrointest Endosc 2013;77:4754.

23. Lee YY, Gwak GY, Lee KH, et al. Predictors of the feasibility of primary endoscopic management of biliary strictures after adult living donor liver transplantation. Liver Transpl 2011;17:1467-1473.

24. Kim TH, Lee SK, Han JH, et al. The role of endoscopic retrograde cholangiography for biliary stricture after adult living donor liver transplantation: technical aspect and outcome. Scand J Gastroenterol 2011;46:188-196.

25. Chang JH, Lee IS, Choi JY, et al. Biliary stricture after adult right-lobe living-donor liver transplantation with duct-to-duct anastomosis: longterm outcome and its related factors after endoscopic treatment. Gut Liver 2010;4:226-233.

26. Kim ES, Lee BJ, Won JY, Choi JY, Lee DK. Percutaneous transhepatic biliary drainage may serve as a successful rescue procedure in failed cases of endoscopic therapy for a post-living donor liver transplantation biliary stricture. Gastrointest Endosc 2009;69:38-46.

27. Kato H, Kawamoto H, Tsutsumi K, et al. Long-term outcomes of endoscopic management for biliary strictures after living donor liver transplantation with duct-to-duct reconstruction. Transpl Int 2009;22:914921.

28. Yazumi S, Yoshimoto T, Hisatsune H, et al. Endoscopic treatment of biliary complications after right-lobe living-donor liver transplantation with duct-to-duct biliary anastomosis. J Hepatobiliary Pancreat Surg 2006;13:502-510.

29. Tsujino T, Isayama H, Sugawara $Y$, et al. Endoscopic management of biliary complications after adult living donor liver transplantation. Am J Gastroenterol 2006;101:2230-2236.

30. Hisatsune H, Yazumi S, Egawa H, et al. Endoscopic management of biliary strictures after duct-to-duct biliary reconstruction in right-lobe living-donor liver transplantation. Transplantation 2003;76:810-815.

31. Parsi MA, Guardino J, Vargo JJ. Peroral cholangioscopy-guided stricture therapy in living donor liver transplantation. Liver Transpl 2009;15:263265.
32. Woo YS, Lee JK, Noh DH, Park JK, Lee KH, Lee KT. SpyGlass cholangioscopy-assisted guidewire placement for post-LDLT biliary strictures: a case series. Surg Endosc 2016;30:3897-3903.

33. De Palma GD, Galloro G, Siciliano S, Iovino P, Catanzano C. Unilateral versus bilateral endoscopic hepatic duct drainage in patients with malignant hilar biliary obstruction: results of a prospective, randomized, and controlled study. Gastrointest Endosc 2001;53:547-553.

34. Polydorou AA, Chisholm EM, Romanos AA, et al. A comparison of right versus left hepatic duct endoprosthesis insertion in malignant hilar biliary obstruction. Endoscopy 1989;21:266-271.

35. Dowsett JF, Vaira D, Hatfield AR, et al. Endoscopic biliary therapy using the combined percutaneous and endoscopic technique. Gastroenterology 1989;96:1180-1186.

36. Lee TH, Kim TH, Moon JH, et al. Bilateral versus unilateral placement of metal stents for inoperable high-grade malignant hilar biliary strictures: a multicenter, prospective, randomized study (with video). Gastrointest Endosc 2017;86:817-827.

37. Vienne A, Hobeika E, Gouya H, et al. Prediction of drainage effectiveness during endoscopic stenting of malignant hilar strictures: the role of liver volume assessment. Gastrointest Endosc 2010;72:728-735.

38. Kerdsirichairat T, Arain MA, Attam R, et al. Endoscopic drainage of $>50 \%$ of liver in malignant hilar biliary obstruction using metallic or fenestrated plastic stents. Clin Transl Gastroenterol 2017;8:e115.

39. Tabibian JH, Asham EH, Han S, et al. Endoscopic treatment of postorthotopic liver transplantation anastomotic biliary strictures with maximal stent therapy (with video). Gastrointest Endosc 2010;71:505512.

40. Tarantino I, Mangiavillano B, Di Mitri R, et al. Fully covered self-expandable metallic stents in benign biliary strictures: a multicenter study on efficacy and safety. Endoscopy 2012;44:923-927.

41. Park DH, Lee SS, Lee TH, et al. Anchoring flap versus flared end, fully covered self-expandable metal stents to prevent migration in patients with benign biliary strictures: a multicenter, prospective, comparative pilot study (with videos). Gastrointest Endosc 2011;73:64-70.

42. Tal AO, Finkelmeier F, Filmann N, et al. Multiple plastic stents versus covered metal stent for treatment of anastomotic biliary strictures after liver transplantation: a prospective, randomized, multicenter trial. Gastrointest Endosc 2017;86:1038-1045.

43. Martins FP, De Paulo GA, Contini MLC, Ferrari AP. Metal versus plastic stents for anastomotic biliary strictures after liver transplantation: a randomized controlled trial. Gastrointest Endosc 2018;87:131.e1-e131.e13.

44. Kaffes A, Griffin S, Vaughan R, et al. A randomized trial of a fully covered self-expandable metallic stent versus plastic stents in anastomotic biliary strictures after liver transplantation. Therap Adv Gastroenterol 2014;7:64-71.

45. Curcio G, Traina M, Miraglia R, Tarantino I, Barresi L, Granata A. Treatment of a refractory biliary stricture after living donor liver transplantation, with a short fully covered metal stent with a long string. Endoscopy 2012;44 Suppl 2 UCTN:E74-E75.

46. Moon JH, Choi HJ, Koo HC, et al. Feasibility of placing a modified fully covered self-expandable metal stent above the papilla to minimize stent-induced bile duct injury in patients with refractory benign biliary strictures (with videos). Gastrointest Endosc 2012;75:1080-1085.

47. Morelli J, Mulcahy HE, Willner IR, Cunningham JT, Draganov P. Longterm outcomes for patients with post-liver transplant anastomotic biliary strictures treated by endoscopic stent placement. Gastrointest Endosc 2003;58:374-379.

48. Rerknimitr R, Sherman S, Fogel EL, et al. Biliary tract complications after orthotopic liver transplantation with choledochocholedochostomy anastomosis: endoscopic findings and results of therapy. Gastrointest Endosc 2002;55:224-231.

49. Morelli G, Fazel A, Judah J, Pan JJ, Forsmark C, Draganov P. Rapid-sequence endoscopic management of posttransplant anastomotic biliary strictures. Gastrointest Endosc 2008;67:879-885. 